\title{
A SCENARIO-BASED OPTIMIZATION MODEL FOR PLANNING AND REDESIGNING THE SALE AND AFTER-SALES SERVICES CLOSED-LOOP SUPPLY CHAIN
}

\author{
Nazanin Esmaeili, Ebrahim Teimour\%* And Fahimeh Pourmohammadi
}

\begin{abstract}
In today's competitive world, the quality of after-sales services plays a significant role in customer satisfaction and customer retention. Some after-sales activities require spare parts and owing to the importance of customer satisfaction, the needed spare parts must be supplied until the end of the warranty period. In this study, a mixed-integer linear optimization model is presented to redesign and plan the sale and after-sales services supply chain that addresses the challenges of supplying spare parts after the production is stopped due to demand reduction. Three different options are considered for supplying spare parts, including production/procurement of extra parts while the product is being produced, remanufacturing, and procurement of parts just in time they are needed. Considering the challenges of supplying spare parts for after-sales services based on the product's life cycle is one contribution of this paper. Also, this paper addresses the uncertainties associated with different parameters through Mulvey's scenario-based optimization approach. Applicability of the model is investigated using a numerical example from the literature. The results indicate that the production/procurement of extra parts and remanufacturing are preferred to the third option. Moreover, remanufacturing is recommended when the remanufacturing cost is less than $23 \%$ of the production cost.
\end{abstract}

Mathematics Subject Classification. 90C11, 90C15.

Received December 14, 2019. Accepted November 15, 2020.

\section{INTRODUCTION}

In today's competitive and globalizing world, offering after-sales services has become an essential competitive advantage and a tool for attracting customers [35]. After-sales services are the set of activities, including maintenance and repair, which occur after purchasing a product and are devoted to supporting customers in the usage and disposal of goods [30]. The quality of after-sales services is a critical factor that influences customer satisfaction and depends on various aspects, including product quality, service response speed, and service cost. Since many maintenance and repair activities require spare parts, spare parts' accessibility can profoundly affect service response speed and hence the perceived quality of after-sales services.

Keywords. Closed-loop supply chain, after-sales services, spare parts supply, scenario-based optimization, Mulvey's optimization approach.

Department of Industrial Engineering, Iran University of Science and Technology, Tehran, Iran.

*Corresponding author: teimoury@iust.ac.ir 
Warranty is the most common type of after-sales services offered to customers in which the manufacturer assures the buyer that the product is or shall be as represented and promises to repair the product (or replace it, if necessary) within a specified period [21]. Since many repair activities require spare parts, fulfilling some warranty obligations depends on spare parts' availability. When a product is being produced, its spare parts can be produced within the same manufacturing system. However, when a product reaches the end of the product life cycle (Decline Stage) and is no longer being manufactured, supplying spare parts becomes more challenging. Various options exist for responding to spare parts' demand in this period, which include:

- Producing or purchasing extra spare parts while the product and its components are still being manufactured;

- Outsourcing after-sales services or the production of spare parts;

- Cannibalization of healthy parts from returned products;

- Remanufacturing defective parts from returned products or the parts customers leave at service centers.

This paper studies the supply chain of sales and after-sales services and proposes a model for redesigning and planning the closed-loop supply chain. Considering the challenges of supplying spare parts for after-sales services based on the product's life cycle is one contribution of this paper. For this aim, the planning horizon is divided into two periods (based on the availability of production facilities), and different options for supplying spare parts are considered for each period. The proposed model determines the optimal location and capacity of collecting/remanufacturing centers, the purchasing amount of raw materials, and the quantity of production, remanufacturing, and transportation between supply chain members.

The after-sales services supply chain faces many uncertainties, including the return rate of products, cause of failure, required spare parts, repair cost, and repair time. The sales supply chain, which is the forward chain, faces some other uncertainties, including demand's quantity, costs, and exchange rate. Since design decisions are strategic decisions with long-term effects on a supply chain's performance, considering these uncertainties is crucial.

In this paper, three parameters, including demand, the return rate, and failure causes, are uncertain. The scenario-based optimization approach developed by Mulvey et al. [20] has been employed to deal with existing uncertainties. This method simultaneously minimizes the mean value and the variance of the objective function under all scenarios using a weighted approach (minimizing problems). Since the objective function of Mulvey's method is non-linear, several researchers have proposed different approaches to obtain the standard deviation of solutions. In the present study, the approach proposed by Yu and Li [36] has been employed.

Section 2 presents the literature review. In Section 3, the scenario-based optimization approach developed by Mulvey et al. [20] is explained. The uncertain model is presented and described in Section 4. Section 5 is dedicated to results, and finally, Section 6 presents the conclusions.

\section{Literature REVIEW}

In this section, related literature regarding reverse logistics and closed-loop supply chain network design, as well as after-sales services network design, are reviewed. Du and Evans [5] considered outsourcing aftersales services to a third-party logistics provider and developed a bi-objective mathematical model to find the optimal capacity of different facilities. Mutha and Pokharel [22] proposed a multi-objective mathematical model for reverse logistics network design. They assumed that returned products are collected at the warehouses for inspection before being sent to the reprocessing center.

Pishvaee and Torabi [25] presented a two-objective mixed-integer optimization model for a closed-loop supply chain network design and employed the fuzzy programming approach to obtain Pareto optimal solutions. Piplani and Saraswat [24] presented a linear mixed-integer optimization model to design a service network that provides repair and refurbishment services. They validated their work using real data of a computer manufacturer. Vahdani et al. [34] investigated the closed-loop network design problem in the scrap metal recycling industry. They proposed a mixed-integer non-linear optimization model and dealt with the uncertainties using a possibilistic programming approach. 
Amin and Zhang [1] developed a linear mixed-integer optimization model for designing a multi-product closedloop supply chain network, which includes collecting and recycling centers, production plants, and customer zones. Ramezani et al. [28] developed a multi-objective probabilistic model for designing a closed-loop supply chain network. The proposed model aims to maximize profit and responsiveness while minimizing defective parts received from suppliers. Ashayeri et al. [2] presented a non-linear mixed-integer optimization model for the after-sales services network design in which after-sales services are outsourced to a third-party logistics provider.

John et al. [16] presented a linear mixed-integer optimization model for the multi-echelon reverse logistics network design considering three options for returned products: remanufacturing, repair, and recycling. Soleimani et al. [33] addressed a closed-loop supply chain's network design problem, including suppliers, manufacturers, customers, distribution centers, warehouse centers, return centers, and recycling centers. The proposed model considers profits as well as environmental requirements. Liao [17] developed a mixed-integer non-linear optimization model for a multi-echelon reverse logistics network design and used a hybrid Genetic Algorithm to obtain optimal solutions. They considered different options for returned products, including repair, remanufacturing, recycling, and reuse.

SahebJamnia et al. [31] presented a multi-objective mixed-integer optimization model for designing a sustainable closed-loop network, considering the environmental impacts of processing tires. Zeballos et al. [37] developed a two-stage mixed-integer linear optimization model for designing a closed-loop supply chain network, considering the uncertainties associated with the quality and quantity of the returned products. Ghahremani-Nahr et al. [13] presented a mixed-integer non-linear optimization (MINLP) model for designing a closed-loop supply chain that minimizes total costs. They considered the uncertainties of demand, the quantity of returned products, transportation costs, the purchasing price of raw materials, and shortage costs using the robust fuzzy programming approach (RFP).

Fakhrzad and Goodrazian [7] developed a multi-objective mixed-integer linear optimization model (MOMILP) for designing a multi-product, multi-period, and multi-level green closed-loop supply chain network. Moreover, they employed a new fuzzy multi-objective optimization approach to deal with uncertain parameters. Fazli Khalaf et al. [11] presented a bi-objective mathematical optimization model for the water distribution network design, which maximizes the total profit and priority of water transferring among demand points. They employed a robust possibilistic programming approach to cope with the uncertainty of parameters.

Liao et al. [18] developed a multi-objective dual-channel supply chain network model to extend the traditional location-inventory problem to consider online customers. They proposed a heuristic solution integrating the Genetic Algorithm, clustering analysis, and a Non-dominated Sorting Genetic Algorithm II to solve the problem. Fazli Khalaf et al. [12] devised a reliable closed-loop supply chain network and introduced a reliability method to tackle different types of disruptions. They considered the uncertainties by developing a robust possibilistic programming (RPP) model. Rezaie et al. [29] presented a multi-objective mathematical model for supply chain network design considering new product development. They applied an improved multi-choice goal programming method to solve the problem.

Fazli-Khalaf and Nemati [9] developed a bi-objective multi-period supplier selection model to minimize total costs and maximize social responsibility. They utilized a chance-constrained possibilistic optimization model to cope with uncertain parameters. Fazli-Khalaf et al. [10] presented a bi-objective reliable supply chain network design to minimize costs and maximize the reliability of the supply chain's facilities and responsiveness. Also, the fuzzy flexible programming method was employed to deal with uncertainties. Majumder et al. [19] developed a single-vendor multi-buyer supply chain model considering variable production rate, aiming to minimize total costs while reducing lead times.

Hamidieh et al. [14] presented a bi-objective optimization model for the supply chain network design problem. The proposed model aims to minimize total costs while maximizing the responsiveness of the supply chain. They applied the stochastic scenario-based optimization approach to deal with uncertainties. Fazli-Khalaf and Hamidieh [8] developed a reliable multi-echelon closed-loop network design model to maximize social responsibilities and minimize costs. They implemented a hybrid robust stochastic optimization approach to tackle the 
uncertainties that are associated with different parameters. Dehghani et al. [4] presented a mixed-integer nonlinear optimization model for the location-inventory problem in a distribution supply chain. A hybrid Markov process was proposed as the solution method. Also, they employed a robust possibilistic programming approach to cope with uncertain parameters.

Table 1 presents a brief review of the papers mentioned above. As shown in Table 1, closed-loop supply chains have received the attention of many researchers in recent years. Although in the beginning, single-period and single-product supply chains were popular, nowadays, many researchers investigate multi-product chains. Also, the majority of papers have considered the uncertainties through stochastic and robust optimization approaches. To the best of our knowledge, the challenges of supplying spare parts for after-sales services have not been addressed in supply chain network design. Moreover, considering the competition between service centers, optimizing pricing decisions while optimizing strategic decisions, and offering multiple options to customers when receiving repairing services can be addressed for future research.

This paper proposes a model for redesigning and planning sales and after-sales services supply chain. Previous studies assume spare parts are always accessible during the warranty period. However, some spare parts are no longer manufactured when a product reaches the decline stage. Thus, this model considers the accessibility of spare-parts by dividing the planning horizon into two periods. The first period starts from the beginning of a product's life cycle and ends with the decline stage (when the product's manufacturing is stopped). The second period continues from that point to the end of the warranty period. Each period consists of some sub-periods in which parameters' values, including demand and return rate, might differ. Three different options are considered for supplying spare parts, which include (1) production/procurement of extra parts while the product is being produced, (2) remanufacturing defective parts, and (3) procurement of spare parts just in time they are needed (at a higher price). Option 1 is only available during the first period, and options 2 and 3 can be considered for supplying spare parts in the second period.

\section{MulveY's SCENARIO-BASED OPTIMIZATION APPROACH}

In the literature, there are some approaches to cope with uncertainty in optimization problems [27]. In 1995, Mulvey et al. [20] proposed a flexible approach for representing scenario-based stochastic optimization models that penalizes the feasibility shortfall in scenario-related constraints. Consider the following mathematical optimization model:

$$
\begin{aligned}
& \min \Gamma(x, y)=c^{T} x+d^{T} y \\
& \text { s.t. } \\
& A x=b \\
& B x+C y=e \\
& x, y \geq 0 .
\end{aligned}
$$

Equation (3.1) is the objective function that aims to minimize total costs. Equations (3.2) and (3.3) represent the constraints of the mathematical optimization problem. Equation (3.2) denotes deterministic parameters, while equation (3.3) contains uncertain parameters. Equation (3.4) defines decision variables in which $x$ represents design variables and $y$ represents controlling variables.

Now assume that set $\Omega$ indicates different scenarios and is defined as $\Omega=\{1,2, \ldots, s\}$. The probability of each scenario is $p_{s}$, and we assume that $\left(\sum_{s} p_{s}=1\right)$. We represent uncertain parameters $B, C, e$ as $B_{s}, C_{s}$, $e_{s}$ for each scenario $(s \in \Omega)$. $\left\{z_{1}, z_{2}, \ldots, z_{s}\right\}$ is the set of error variables that show the infeasibility degree for infeasible constraints and $\omega$ represents the penalty. Then, the mathematical model suggested by Mulvey et al. 


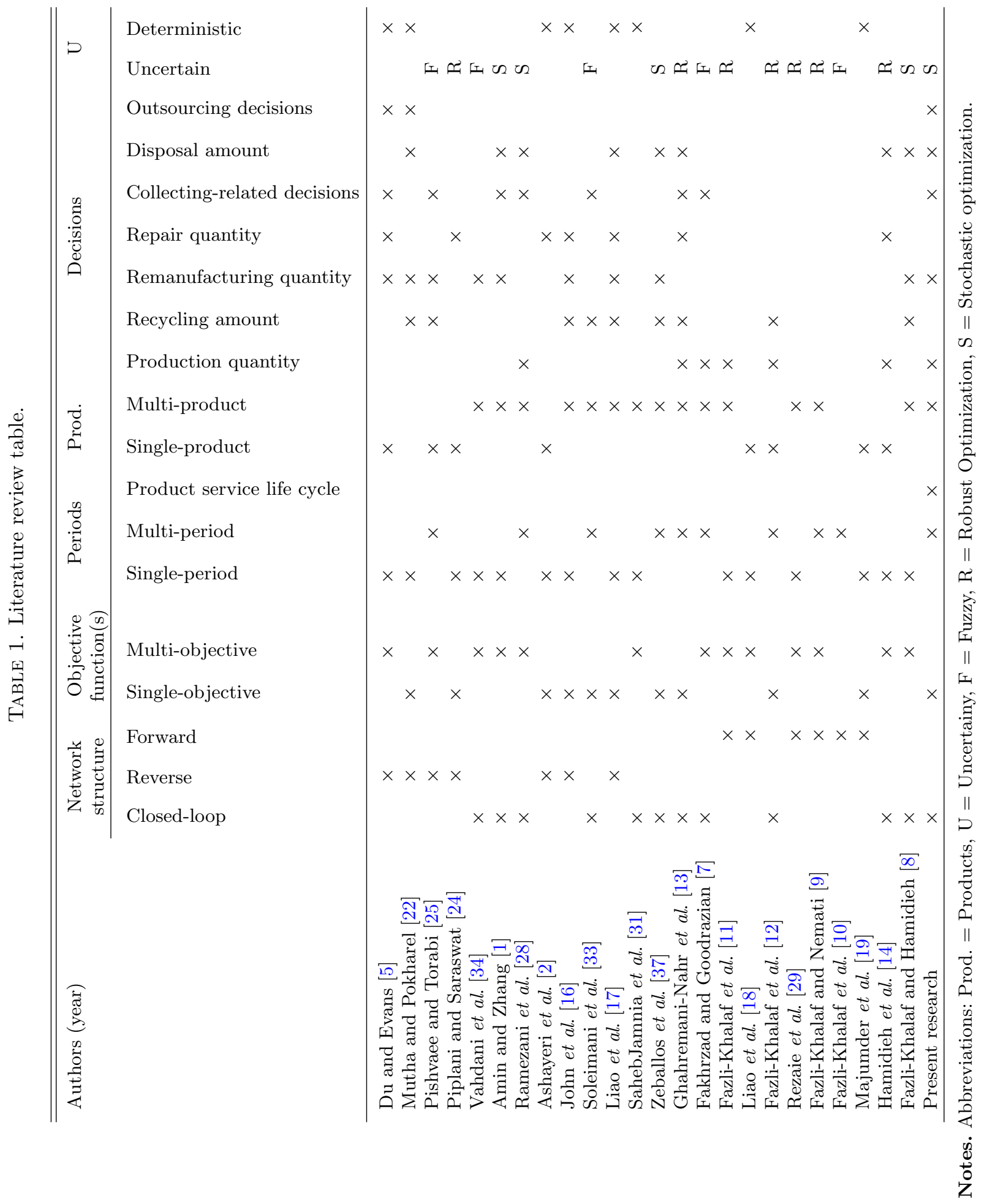


$[20]$ is as follows:

$$
\begin{aligned}
& \min \sigma\left(x, y_{s}\right)+\omega p\left(z_{1}, z_{2}, \ldots, z_{s}\right) \\
& \text { s.t. } \\
& A x=b \\
& B_{s} x+C_{s} y_{s}+z_{s}=e_{s} \quad \forall s \in \Omega \\
& x, y_{s}, z_{s} \geq 0 \quad \forall s \in \Omega .
\end{aligned}
$$

In which:

$$
\sigma\left(x, y_{s}\right)=\lambda \sum_{s \in \Omega} p_{s} \Gamma_{s}+(1-\lambda) \sum_{s \in \Omega} p_{s}\left(\Gamma_{s}-\sum_{s \in \Omega} p_{s} \Gamma_{s}\right)^{2} .
$$

Equation (3.5) represents the new objective function, which minimizes the summation of $\sigma\left(x, y_{s}\right)$ and infeasibility penalty. $\sigma\left(x, y_{s}\right)$ is presented in equation (3.9) and calculates a weighted summation of the mean and the variance of cost functions. $\Gamma$ is the cost function, which is defined as $\Gamma_{s}=f\left(x, y_{s}\right)$ for each scenario. $\sum_{s \in \Omega} p_{s} \Gamma_{s}$ calculates the mean of cost functions, and $\sum_{s \in \Omega} p_{s}\left(\Gamma_{s}-\sum_{s \in \Omega} p_{s} \Gamma_{s}\right)^{2}$ calculates the variance. $\lambda$ is the weight given by the decision-maker, and indicates the relative importance of the mean of objectives in comparison to the variance. When the variance increases, the decision making becomes riskier.

As equation (3.6) only denotes deterministic parameters, it does not change, but equation (3.7) is allowed some infeasibility. $\left\{z_{1}, z_{2}, \ldots, z_{s}\right\}$ is the set of error variables that show the infeasibility degree of equation (3.7). The decision-maker may omit this set in situations where infeasibility is undesirable. Since the objective function (3.5) is non-linear, it increases the complexity of problems. Hence, Yu and Li [36] proposed another approach to obtain the standard deviation of solutions which is as follows:

$$
\sigma^{\prime}\left(x, y_{s}\right)=\lambda \sum_{s \in \Omega} p_{s} \Gamma_{s}+(1-\lambda) \sum_{s \in \Omega} p_{s}\left|\Gamma_{s}-\sum_{s \in \Omega} p_{s} \Gamma_{s}\right| .
$$

Then equation (3.10) can be rewritten as follows using positive variables $\partial_{s}$ :

$$
\begin{aligned}
& \sigma^{\prime}\left(x, y_{s}\right)=\lambda \sum_{s \in \Omega} p_{s} \Gamma_{s}+(1-\lambda) \sum_{s \in \Omega} p_{s}\left[\left(\Gamma_{s}-\sum_{s \in \Omega} p_{s} \Gamma_{s}\right)+2 \partial_{s}\right] \\
& \left(\Gamma_{s}-\sum_{s^{\prime} \in \Omega} p_{s^{\prime}} \Gamma_{s^{\prime}}\right)+\partial_{s} \geq 0 \quad \forall s \in \Omega \\
& \partial_{s} \geq 0 \quad \forall s \in \Omega .
\end{aligned}
$$

Note that equation (3.11) is the linear objective function, and constraints (3.12) and (3.13) calculate $\partial_{s}$ and should also be added to the mathematical model.

\section{The PROpOSED MODEL}

In this section, the problem is described, and used notation, including indices, parameters, and decision variables are introduced. Then, the objective function and constraints are discussed.

\subsection{Problem statement}

Consider an original equipment manufacturer (OEM) that produces multiple multi-indenture products and offers after-sales services as a tool to attract customers. Thus, when products fail, customers can return the products to service centers for repair. In these centers, every product is inspected to determine the defective 
part(s). Once the defective parts are identified, they are replaced with new parts. The defective parts remain at service centers to be safely destroyed. The OEM supplies demanded parts at service centers by producing or purchasing them from other suppliers.

While the products are still being produced, supplying their components faces no difficulties since they can be produced within the same manufacturing facilities or by the same suppliers. However, when a product reaches the decline stage and is no longer being manufactured, supplying its components becomes more challenging. Until now, the OEM had two options for supplying needed parts: (1) producing or purchasing more parts (at a lower price) while the product and its components were still being produced and storing them for later consumption, and (2) purchasing parts just in time they were needed (at a higher price) from other suppliers. However, there is a pile of defective parts at service centers that the OEM can remanufacture, requiring opening new facilities for collection and remanufacturing.

In this research, two main periods are considered for modeling the challenges of supplying spare parts:

- From the beginning of the production to the decline stage when production stops (Period I).

- From that point to the end of the warranty period (Period II).

The closed-loop supply chain network considered in the present study is shown in Figure 1. In this chain, the components of products are produced in manufacturing facilities using raw materials that are purchased from suppliers. Then the manufactured parts are transferred to the main production center (OEM) where products are being assembled, stored, and later transferred to retailers to be sold to customers. Also, the production center can purchase parts directly from suppliers if needed.

When a product fails, the customer can return the product to service centers for repair. In these centers, every product is inspected to determine the defective part(s). Once the defective parts are identified, they are replaced with new parts. Service centers transfer defective parts to collecting/remanufacturing centers where they are inspected to determine if they can be remanufactured. Defective parts that can be remanufactured are stored, and the rest are safely destroyed. It should be noted that collecting/ remanufacturing centers do not remanufacture in Period I when the parts are still being produced. In fact, collecting/ remanufacturing $(\mathrm{C} / \mathrm{R})$ centers collect and inspect during the first period, and during Period II, they carry out collection, inspection, and remanufacturing operations.

The proposed model for redesigning and planning of the closed-loop supply chain of sales and after-sales services aims to minimize total costs of the chain while determining the optimal location and capacity of collecting/remanufacturing centers, the purchasing amount of raw materials, and the quantity of production, remanufacturing, and transportation between members of the supply chain. Moreover, demand, the return rate, and the cause of failure are uncertain.

Other assumptions are as follows:

- The OEM is responsible for providing spare parts for after-sales services.

- Parts and products can only be produced in Period I.

- Defective parts can only be remanufactured in Period II.

- Damaged products are repaired by replacing the defective parts(s).

- Not all defective parts can be remanufactured. Also, collecting/remanufacturing centers may not remanufacture all defective parts.

- The remanufactured parts are as good as new parts.

- In Period II, spare parts can be purchased from suppliers at a higher price.

- The beginning and end of Period I and Period II may differ for different products.

\subsection{Notation}

Indices, parameters, and decision variables used in the proposed model are as follows: 


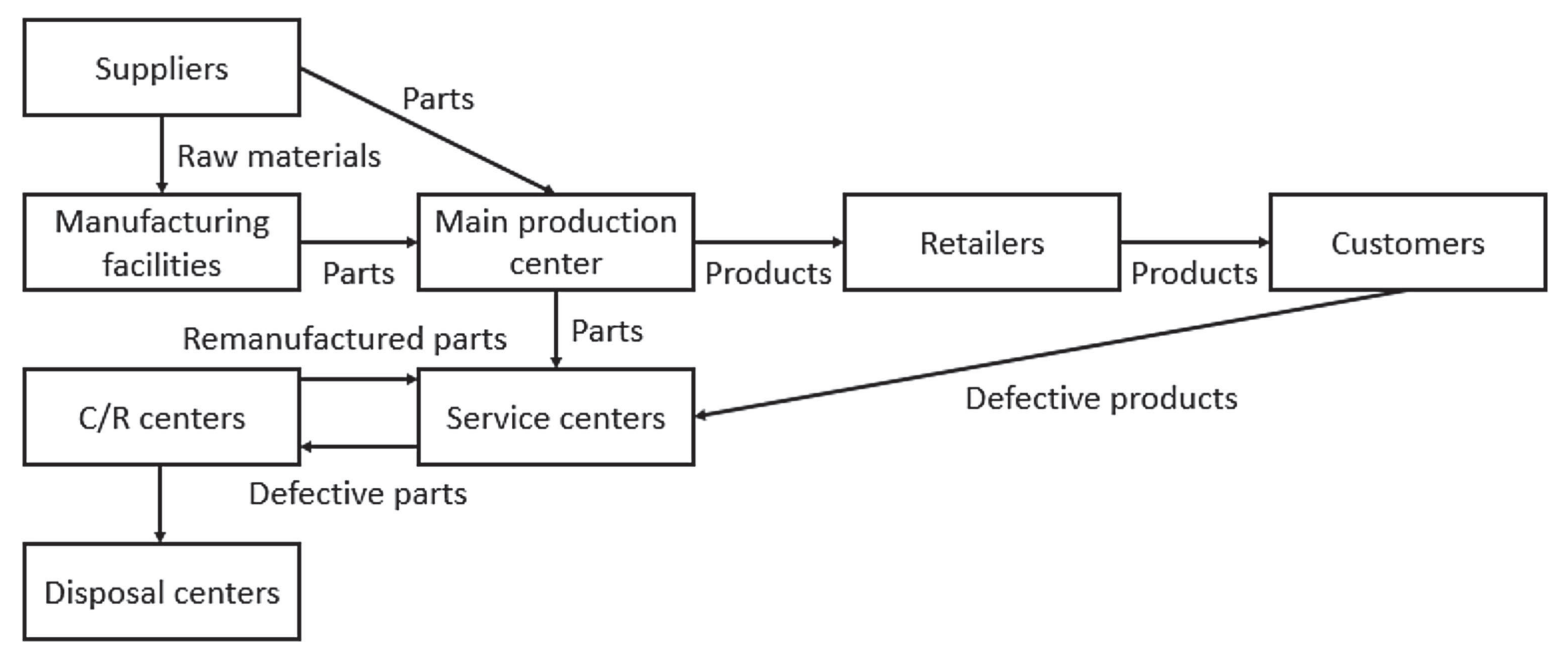

Figure 1. The closed-loop supply chain of sales and after-sales services.

\section{Indices and sets}

$l \in\{1, \ldots, L\}$ Suppliers.

$c \in\{1, \ldots, C\}$ Potential locations for collecting/remanufacturing centers.

$r \in\{1, \ldots, R\}$ Retailers.

$s \in\{1, \ldots, S\}$ Service centers.

$p \in\{1, \ldots, P\}$ Manufacturing facilities.

$i \in\{1, \ldots, I\}$ Products.

$j \in\{1, \ldots, J\}$ Parts.

$m \in\{1, \ldots, M\}$ Raw materials.

$t \in\left\{1, \ldots, T_{0 i}, \ldots, T_{1 i}, \ldots, T_{2 i}, \ldots, T\right\}$ Periods: Period $\mathrm{I}_{i}=\left\{T_{0 i}, \ldots, T_{1 i}\right\}$ and Period $\mathrm{II}_{i}=\left\{T_{1 i}+1, \ldots, T_{2 i}\right\}$

( $T_{1 i}$ determines the period in which the production of product $i$ stops while $\left(T_{2 i}\right.$ determines the end of the warranty period for product $i$ ).

$v \in\{1, \ldots, V\}$ Capacity levels.

$\theta, \theta^{\prime}$ Scenarios.

\section{Parameters}

$D_{\text {irt } \theta}$ The demand of retailer $r$ for product $i$ in period $t$ under scenario $\theta$.

$\mathrm{RP}_{i s t \theta}$ Return rate: the quantity of products type $i$ needing repair at service center $s$ in period $t$ under scenario $\theta$.

$\alpha_{i j \theta}$ The probability that part $j$ is the cause of failure in product $i$ under scenario $\theta$.

$\varphi_{i j}$ The required quantity of part $j$ for assembling product $i$.

$\varphi_{j m}^{\prime}$ The required amount of raw material $m$ for producing part $j$.

$\pi_{i j}$ Percentage of the defective parts $j$ from product $i$ which can be remanufactured.

$\mathrm{RPC}_{j l t}$ The purchasing cost of part $j$ from supplier $l$ in period $t$.

$\mathrm{RPCM}_{m l t}$ The purchasing cost of raw material $m$ from supplier $l$ in period $t$.

$\mathrm{PRCO}_{i t}$ Producing cost of product $i$ in period $t$.

PRCOJ $_{j p t}$ Producing cost of part $j$ in period $t$ at manufacturing facility $p$.

$\mathrm{PRC}_{j c t}$ Remanufacturing cost of part $j$ in period $t$ at collecting/remanufacturing center $c$.

$\mathrm{SV}_{j t}$ Salvage value of part $j$ in period $t$ (is negative if safe disposal of part $j$ has costs).

$\mathrm{HCPO}_{i t}$ Holding cost of product $i$ in period $t$ at the main production center. 
$\mathrm{HCSO}_{j t}$ Holding cost of a new part $j$ in period $t$ at manufacturing facilities and the main production center.

$\operatorname{HCSS}_{j t}$ Holding cost of a new part $j$ in period $t$ at service centers.

$\mathrm{HCSC}_{j t}$ Holding cost of a defective part $j$ at collecting/remanufacturing centers in period $t$.

$\mathrm{HCRC}_{j t}$ Holding cost of a remanufactured part $j$ at collecting/remanufacturing centers in period $t$.

$\mathrm{HCMP}_{m t}$ Holding cost of raw material $m$ at manufacturing facilities in period $t$.

$\mathrm{TC}_{i r t}$ Transportation cost of product $i$ from the main production center to retailer $r$ in period $t$.

$\mathrm{TCB}_{j l t}$ Transportation cost of a new part $j$ from supplier $l$ to the main production center in period $t$.

$\mathrm{TCM}_{m l p t}$ Transportation cost of raw material $m$ from supplier $l$ to manufacturing facility $p$ in period $t$.

TCBJ $_{j p t}$ Transportation cost of a new part $j$ from manufacturing facility $p$ to the main production center in period $t$.

$\mathrm{TCN}_{j s t}$ Transportation cost of a new part $j$ from the main production center to service center $s$ in period $t$.

$\mathrm{TCR}_{j c s t}$ Transportation cost of a new part $j$ from collecting/remanufacturing center $c$ to service center $s$ in period $t$.

$\mathrm{TCF}_{j s c t}$ Transportation cost of a defective part $j$ from service center $s$ to collecting/remanufacturing center $c$ in period $t$.

$\mathrm{IC}_{j}$ Inspection cost of part $j$ in collecting/remanufacturing center.

$\operatorname{Dlp}_{l p}$ Distance between supplier $l$ and manufacturing facility $p$.

$\mathrm{Dpo}_{p}$ Distance between manufacturing facility $p$ and the main production center.

$\mathrm{Dso}_{l}$ Distance between supplier $l$ and the main production center.

Dor $_{r}$ Distance between the main production center and retailer $r$.

Dos $_{s}$ Distance between the main production center and service center $s$.

$\operatorname{Dsc}_{s c}$ Distance between service center $s$ and remanufacturing center $c$.

$\mathrm{Capj}_{j p t}$ The production capacity of part $j$ at manufacturing facility $p$ in period $t$.

$\mathrm{Capm}_{p}$ The capacity of manufacturing facility $p$ for holding raw materials.

Capnop $_{p}$ The capacity of manufacturing facility $p$ for holding parts.

Capml $_{m l t}$ The supplying capacity of supplier $l$ for raw material $m$ in period $t$.

$\mathrm{Cap}_{i t}$ The production capacity of product $i$ at the main production center in period $t$.

$\operatorname{Capr}_{j c v}$ The remanufacturing capacity of part $j$ at collecting/remanufacturing center $c$ with a capacity level $v$.

Cappo The capacity of the main production center for holding products.

Capno The capacity of the main production center for holding parts.

Capfe $_{c v}$ The capacity of collecting/remanufacturing center $c$ with capacity level $v$ for holding defective parts.

Caprc $_{c v}$ The capacity of collecting/remanufacturing center $c$ with capacity level $v$ for holding remanufactured parts.

Capns $_{s}$ The capacity of service center $s$ for holding parts.

$\operatorname{Capl}_{j l t}$ The supplying capacity of supplier $l$ for part $j$ in period $t$.

$\mathrm{CC}_{c v}$ Opening cost of collecting/remanufacturing center $c$ with a capacity level $v$.

$\mathrm{FC}_{t}$ Fixed cost of supplier selection in period $t$.

$\mathrm{BN}$ Big number.

$\mathrm{DP}_{i}$ The volume of product $i$.

$\mathrm{DI}_{j}$ The volume of part $j$.

$\mathrm{DM}_{m}$ The volume of raw material $m$.

$\xi_{\theta}$ Probability of scenario $\theta$.

$\lambda$ Mulvey's coefficient.

\section{Decision variables}

$\mathrm{QM}_{m l p t \theta}$ The amount of raw material $m$ transported from supplier $l$ to manufacturing facility $p$ in period $t$ under scenario $\theta$.

$\mathrm{QJ}_{j p t \theta}$ Quantity of part $j$ produced by manufacturing facility $p$ in period $t$ under scenario $\theta$. 
$\mathrm{QPO}_{j p t \theta}$ Quantity of part $j$ transported from manufacturing facility $p$ to the main production center in period $t$ under scenario $\theta$.

$\mathrm{QB}_{j l t \theta}$ Quantity of part $j$ transported from supplier $l$ to the main production center in period $t$ under scenario $\theta$.

$\mathrm{QP}_{i t \theta}$ Quantity of product $i$ produced in the main production center in period $t$ under scenario $\theta$.

$\mathrm{QOS}_{j s t \theta}$ Quantity of new product $j$ transported from OEM to service center $s$ in period $t$ under scenario $\theta$.

$\mathrm{QSC}_{j s c t \theta}$ Quantity of defective part $j$ transported from service center $s$ to collecting/remanufacturing center $c$ in period $t$ under scenario $\theta$.

$\mathrm{QRS}_{j c s t \theta}$ Quantity of remanufactured part $j$ transported from collecting/remanufacturing center $c$ to service center $s$ in period $t$ under scenario $\theta$.

$\mathrm{QR}_{j c t \theta}$ Quantity of part $j$ remanufactured by collecting/remanufacturing center $c$ in period $t$ under scenario $\theta$. $\operatorname{Invm}_{m p t \theta}$ Inventory of raw material $m$ in manufacturing facility $p$ in period $t$ under scenario $\theta$.

Invnoj $_{j p t \theta}$ Inventory of new part $j$ in manufacturing facility $p$ in period $t$ under scenario $\theta$.

$\operatorname{Invpo}_{i t \theta}$ Inventory of product $i$ in the main production center in period $t$ under scenario $\theta$.

Invno $_{j t \theta}$ Inventory of new part $j$ in the main production center in period $t$ under scenario $\theta$.

$\operatorname{Invfc}_{j c t \theta}$ Inventory of defective part $j$ in collecting/remanufacturing center $c$ in period $t$ under scenario $\theta$.

$\operatorname{Invrc}_{j c t \theta}$ Inventory of remanufactured part $j$ in collecting/remanufacturing center $c$ in period $t$ under scenario $\theta$. Invns $_{j s t \theta}$ Inventory of new part $j$ in service center $s$ in period $t$ under scenario $\theta$.

$\operatorname{Dis}_{j c t \theta}$ Quantity of part $j$ which cannot be remanufactured and is disposed of in collecting/remanufacturing center $c$ in period $t$ under scenario $\theta$.

$\operatorname{Disv}_{j c t \theta}$ Quantity of part $j$ which is not needed and is disposed of in collecting/remanufacturing center $c$ in period $t$ under scenario $\theta$.

$y_{c v}$ Equals 1 if the collecting/remanufacturing center $c$ with capacity level $v$ is opened, otherwise 0 .

$y_{l t}$ Equals 1 if supplier $l$ is selected in period $t$.

$\omega_{\theta}$ Linearization variable.

$z_{\theta}$ Total costs under scenario $\theta$.

$Z^{\prime}$ The objective function of Mulvey's method.

\subsection{Objective function and model constraints}

In this paper, the scenario-based optimization approach developed by Mulvey et al. [20] has been employed to deal with existing uncertainties. It should be noted that in this study, the optimal solution is feasible under all scenarios. The objective function and constraints are as follows:

$$
\begin{aligned}
\mathrm{MIN} Z^{\prime}= & \lambda \sum_{\theta} \xi_{\theta} \cdot z_{\theta}+(1-\lambda) \cdot \sum_{\theta} \xi_{\theta}\left[\left(z_{\theta}-\sum_{\theta} \xi_{\theta} \cdot z_{\theta}\right)+2 \omega_{\theta}\right] \\
z_{\theta}= & \sum_{i} \sum_{j} \sum_{l} \sum_{t}\left(\mathrm{RPC}_{j l t} \cdot \mathrm{QB}_{j l t \theta}+\mathrm{PRCO}_{i t} \cdot \mathrm{QP}_{i t \theta}\right) \\
& +\sum_{j} \sum_{l} \sum_{m} \sum_{p} \sum_{t}\left(\mathrm{RPCM}_{m l t} \cdot \mathrm{QM}_{m l p t \theta}+\mathrm{PRCOJ}_{j p t} \cdot \mathrm{QJ}_{j p t \theta}\right) \\
& +\sum_{i} \sum_{j} \sum_{p} \sum_{t}\left(\mathrm{HCPO}_{i t} \cdot \operatorname{Invpo}_{i t \theta}+\mathrm{HCSO}_{j t} \cdot\left(\operatorname{Invno}_{j t \theta}+\operatorname{Invnoj}_{j p t \theta}\right)\right) \\
& +\sum_{j} \sum_{s} \sum_{c} \sum_{t}\left(\mathrm{HCSS}_{j t} \cdot \operatorname{Invns}_{j s t \theta}+\mathrm{HCSC}_{j t} \cdot \operatorname{Invfc}_{j c t \theta}\right) \\
& +\sum_{j} \sum_{c} \sum_{m} \sum_{p} \sum_{t}\left(\mathrm{HCRC}_{j t} \cdot \operatorname{Invrc}_{j c t \theta}+\mathrm{HCMP}_{m t} \cdot \operatorname{Invm}_{m p t \theta}\right) \\
& +\sum_{j} \sum_{c} \sum_{t} \mathrm{PRC}_{j c t} \cdot \mathrm{QR}_{j c t \theta}-\sum_{j} \sum_{c} \sum_{t} \mathrm{SV}_{j t} \cdot\left(\operatorname{Dis}_{j c t \theta}+\operatorname{Disv}_{j c t \theta}\right) \\
& +\sum_{j} \sum_{p} \sum_{m} \sum_{l} \sum_{t}\left(\mathrm{TCBJ}_{j p t} \cdot \mathrm{Dpo}_{p} \cdot \mathrm{QPO}_{j p t \theta}+\mathrm{TCM}_{m l p t} \cdot \operatorname{Dlp}_{l p} \cdot \mathrm{QM}_{m l p t \theta}\right)
\end{aligned}
$$




$$
\begin{aligned}
& +\sum_{i} \sum_{j} \sum_{l} \sum_{r} \sum_{t}\left(\mathrm{Dso}_{l} \cdot \mathrm{TCB}_{j l t} \cdot \mathrm{QB}_{j l t \theta}+\mathrm{Dor}_{r} \cdot \mathrm{TC}_{i r t} \cdot \mathrm{QOR}_{i r t \theta}\right) \\
& +\sum_{j} \sum_{s} \sum_{c} \sum_{t}\left(\operatorname{Dos}_{s} \cdot \mathrm{TCN}_{j s t} \cdot \mathrm{QOS}_{j s t \theta}+\mathrm{Dsc}_{s c} \cdot \mathrm{TCR}_{j c s t} \cdot \mathrm{QRS}_{j c s t \theta}\right. \\
& \left.+\mathrm{Dsc}_{s c} \cdot \mathrm{TCF}_{j s c t} \cdot \mathrm{QSC}_{j s c t \theta}\right) \\
& +\sum_{c} \sum_{v} \mathrm{CC}_{c v} \cdot y_{c v}+\sum_{j} \sum_{s} \sum_{c} \sum_{t} \mathrm{IC}_{j} \cdot \mathrm{QSC}_{j s c t \theta}+\sum_{t} \sum_{l} \mathrm{FC}_{t} \cdot y_{l t}
\end{aligned}
$$

s.t. :

$$
\left(z_{\theta}-\sum_{\theta^{\prime}} \xi_{\theta^{\prime}} \cdot z_{\theta^{\prime}}\right)+\omega_{\theta} \geq 0 \quad \forall \theta
$$

$\operatorname{Invpo}_{i t \theta}=\operatorname{Invpo}_{i, t-1, \theta}+\mathrm{QP}_{i t \theta}-\sum_{r} D_{r t \theta} \quad \forall i, \theta, t \in$ Period I

$\mathrm{Invno}_{j t \theta}=\operatorname{Invno}_{j, t-1, \theta}+\sum_{l} \mathrm{QB}_{j l t \theta}+\sum_{p} \mathrm{QPO}_{j p t \theta}-\sum_{i} \varphi_{i j} \mathrm{QP}_{i t \theta}-\sum_{s} \mathrm{QOS}_{j s t \theta} \quad \forall j, \theta, t \in$ Period I

$\operatorname{Invfc}_{j c t \theta}=\sum_{s} \mathrm{QSC}_{j s c t \theta}+\operatorname{Invfc}_{j c, t-1, \theta}-\operatorname{Dis}_{j c t \theta} \quad \forall j, c, \theta, t \in$ Period I

$\operatorname{Dis}_{j c t \theta}=\sum_{i} \sum_{s}\left(1-\pi_{i j}\right) \cdot \mathrm{QSC}_{j s c t \theta} \quad \forall j, c, t, \theta$

$\operatorname{Invfc}_{j c t \theta}=\sum_{s} \mathrm{QSC}_{j s c t \theta}+\operatorname{Invfc}_{j c, t-1, \theta}-\operatorname{Dis}_{j c t \theta}-\operatorname{Disv}_{j c t \theta}-\mathrm{QR}_{j c t \theta} \quad \forall j, c, \theta, t \in$ Period II

$\sum_{j, s} \mathrm{QSC}_{j s c t \theta}=\mathrm{BN} \cdot \sum_{v} y_{c v} \quad \forall c, \theta, t \in$ Period II

$\operatorname{Invrc}_{j c t \theta}=\operatorname{Invrc}_{j c, t-1, \theta}+\mathrm{QR}_{j c t \theta}-\sum_{s} \mathrm{QRS}_{j c s t \theta} \quad \forall j, c, \theta, t_{i} \in\left\{T_{1 i}+1, \ldots, T_{2 i}\right\}$

$\sum_{c} \mathrm{QSC}_{j s c t \theta}=\sum_{i} \varphi_{i j} \cdot \alpha_{i j \theta} \cdot \mathrm{RP}_{i s t \theta} \quad \forall j, s, t, \theta$

Invns $_{j s t \theta}=\operatorname{Invns}_{j s, t-1, \theta}+\operatorname{QOS}_{j s t \theta}-\sum_{i} \varphi_{i j} \cdot \alpha_{i j \theta} \cdot \mathrm{RP}_{i s t \theta} \quad \forall j, s, \theta, t \in$ Period I

$\operatorname{Invns}_{j s t \theta}=\operatorname{Invns}_{j s, t-1, \theta}+\mathrm{QOS}_{j s t \theta}-\sum_{i} \varphi_{i j} \cdot \alpha_{i j \theta} \cdot \mathrm{RP}_{i s t \theta}+\sum_{c} \mathrm{QRS}_{j c s t \theta} \quad \forall j, s, \theta, t \in$ Period II

$\sum_{i} \mathrm{DP}_{i} \cdot \operatorname{Invpo}_{i t \theta} \leq$ Cappo $\quad \forall t \in$ Period I

$\sum_{j} \mathrm{DI}_{j} \cdot \mathrm{Invno}_{j t \theta} \leq$ Capno $\quad \forall t, \theta$

$\sum_{j} \mathrm{DI}_{j} \cdot \operatorname{Invfc}_{j c t \theta} \leq \sum_{v} \operatorname{Capfc}_{c v} \cdot y_{c v} \quad \forall c, t, \theta$

$\sum_{j} \mathrm{DI}_{j} \cdot \operatorname{Invrc}_{j c t \theta} \leq \sum_{v} \operatorname{Caprc}_{c v} \cdot y_{c v} \quad \forall c, \theta, t \in$ Period II

$\sum_{j} \mathrm{DI}_{j} \cdot \operatorname{Invns}_{j s t \theta} \leq \operatorname{Capns}_{s} \quad \forall s, t, \theta$

$\sum_{j} \mathrm{QR}_{j c t \theta} \leq \sum_{v} \operatorname{Capr}_{c v t} \cdot y_{c v} \quad \forall c, \theta, t \in$ Period II

$\mathrm{QB}_{j l t \theta} \leq \mathrm{Capl}_{j l t} \quad \forall j, l, \theta, t \in$ Period I 


$$
\begin{aligned}
& \mathrm{QP}_{i t \theta} \leq \operatorname{Cap}_{i t} \quad \forall i, \theta, t \in \text { Period I } \\
& \sum_{v} y_{c v} \leq 1 \quad \forall c \\
& \operatorname{Invnoj}_{j p t \theta}=\operatorname{Invnoj}_{j p, t-1, \theta}+\mathrm{QJ}_{j p t \theta}-\mathrm{QPO}_{j p t \theta} \quad \forall j, p, \theta, t \in \text { Period I } \\
& \mathrm{QJ}_{j p t \theta} \leq \operatorname{Capj}_{j p t} \forall j, p, \theta, t \in \operatorname{Period} \mathrm{I} \\
& \sum_{j} \mathrm{DI}_{j} \cdot \operatorname{Invnoj}_{j p t \theta} \leq \text { Capnop }_{p t} \quad \forall p, t, \theta \\
& \operatorname{Invm}_{m p t \theta}=\operatorname{Invm}_{m p, t-1, \theta}-\sum_{j} \varphi_{j m}^{\prime} \cdot \mathrm{QJ}_{j p t \theta}+\sum_{l} \mathrm{QM}_{m l p t \theta} \quad \forall m, p, \theta, t \in \text { Period I } \\
& \sum_{p} \mathrm{QM}_{m l p t \theta} \leq \mathrm{Capml}_{m l t} \quad \forall m, l, \theta, t \in \text { Period I } \\
& \sum_{m} \mathrm{DM}_{m} \cdot \operatorname{Invm}_{m p t \theta} \leq \operatorname{Capm}_{p t} \quad \forall p, \theta, t \in \text { Period I } \\
& \mathrm{QM}_{m l p t \theta} \leq \mathrm{BN} \cdot y_{l t} \quad \forall m, l, p, \theta, t \in \text { Period I } \\
& y_{l t} \leq \mathrm{QM}_{m l p t \theta} \quad \forall m, l, p, \theta, t \in \text { Period I } \\
& \mathrm{QB}_{j l t \theta} \leq \mathrm{BN} \cdot y_{l t} \quad \forall j, l, \theta, t \in \text { Period I } \\
& y_{l t} \leq \mathrm{QB}_{j l t \theta} \quad \forall j, l, \theta, t \in \text { Period I } \\
& \mathrm{QM}_{m l p t \theta}, \mathrm{QJ}_{j p t \theta}, \mathrm{QPO}_{j p t \theta}, \mathrm{QB}_{j l t \theta}, \mathrm{QP}_{i t \theta}, \mathrm{QOS}_{j s t \theta}, \mathrm{QSC}_{j s c t \theta}, \mathrm{QRS}_{j c s t \theta}, \mathrm{QR}_{j c t \theta}, \operatorname{Invm}_{m p t \theta}, \operatorname{Invnoj}_{j p t \theta} \text {, } \\
& \operatorname{Invpo}_{i t \theta}, \operatorname{Invno}_{j t \theta}, \operatorname{Invfc}_{j c t \theta}, \operatorname{Invrc}_{j c t \theta}, \operatorname{Invrc}_{j c t \theta}, \operatorname{Dis}_{j c t \theta}, \operatorname{Disv}_{j c t \theta}, \omega_{\theta} \geq 0, y_{c v}, y_{l t} \in\{0,1\} \text {. }
\end{aligned}
$$

Equation (4.1) is the objective function of Mulvey's approach, which was explained in Section 3. Terms (4.2)(4.11) calculate the total costs of the supply chain under each scenario in which term (4.2) determines the purchasing cost of parts and the producing cost of products. Term (4.3) shows the purchasing cost of raw materials and the cost of producing parts at manufacturing centers, and terms (4.4)-(4.6) calculate the holding cost of parts and products. Term (4.7) shows remanufacturing costs and the salvage value of defective parts, and terms (4.8)-(4.10) determine transportation costs of parts and products. Finally, Term (4.11) shows the cost of opening new facilities, inspection, and supplier selection.

Equation (4.12) is the linearization equation. Note that the index of summation is $\theta^{\prime}$. Equation (4.13) calculates the inventory of final products at the main production center under each scenario. Also, equation (4.14) determines the inventory of parts at the main production center under each scenario. Equation (4.15) states the inventory of defective parts at collecting/remanufacturing centers under each scenario. Equation (4.16) calculates the number of defective parts that cannot be remanufactured and are safely disposed of under each scenario. Equation (4.17) shows the inventory of defective parts at the remanufacturing centers in Period II under each scenario.

Constraint (4.18) guarantees that collecting/remanufacturing centers are only operational if they are opened. Equation (4.19) calculates the inventory of remanufactured products at the collecting/remanufacturing center under each scenario. Equation (4.20) guarantees that all defective parts are sent to collecting/remanufacturing centers. Equation (4.21) shows the inventory of new parts at service centers in Period I under each scenario. Equation (4.22) shows the inventory of new parts at service centers in Period II under each scenario.

Constraint (4.23) shows the capacity of the main production center for holding products. Also, constraint (4.24) determines the capacity of the main production center for holding parts. Constraint (4.25) indicates the capacity of collecting/remanufacturing centers for holding defective parts, while constraint (4.26) indicates the capacity of collecting/ remanufacturing centers for holding remanufactured parts. Constraint (4.27) shows the capacity of service centers for holding parts. Constraint (4.28) expresses the remanufacturing capacity at the collecting/remanufacturing centers. 
TABLE 2. Information regarding the size of the problem.

\begin{tabular}{ll}
\hline \hline Chain member & Number \\
\hline Suppliers & 25 \\
Potential collecting/remanufacturing centers & 5 \\
Retailers & 35 \\
Service centers & 10 \\
Periods & 4, two sub-periods for Period I and two for Period II \\
Products & 2 \\
Parts & 5 \\
Materials & 5 \\
Scenarios & 800, which were grouped into ten fuzzy clusters \\
\hline
\end{tabular}

TABLE 3. Information regarding the size of the coded problem in GAMS and results.

\begin{tabular}{ll}
\hline \hline Single equations & 29449 \\
Single variables & 67533 \\
Non-zero elements & 450886 \\
Discrete variables & 119 \\
Generation time & $15026.204 \mathrm{s.}$ \\
Cplex time & $276.734 \mathrm{~s}$. \\
MIP solution $(\lambda=1)$ & $180293965293725.34(693464$ iterations, 1036 nodes $)$ \\
Final solve $(\lambda=1)$ & 180293965293724.81 (9229 iterations) \\
Absolute gap & 0 \\
Relative gap & 0 \\
\hline
\end{tabular}

Constraint (4.29) guarantees that the quantity of purchased parts from suppliers does not exceed their capacity. Constraint (4.30) determines the production capacity of the main production center. Constraint (4.31) states that only one capacity level can be selected for any new facility. Equations (4.32) and (4.33) are related to the inventory of new parts and production capacity at manufacturing facilities. Constraint (4.34) guarantees that the inventory of new parts at manufacturing facilities does not exceed their capacity under each scenario. Equation (4.35) calculates the inventory of raw materials at manufacturing facilities. Constraint (4.36) determines the suppliers' capacity for raw materials. Constraint (4.37) indicates the capacity of manufacturing facilities for holding raw materials. Constraints (4.38)-(4.41) show that raw materials and parts can only be purchased from selected suppliers. Finally, Equation (4.42) presents the decision variables and their types.

\section{IMPLEMENTATION AND RESULTS}

The proposed model is coded in GAMS 24.1.2 and is solved by CPLEX 12.5.1.0 solver. All tests are carried out on an Intel Core i5 @ $2.53 \mathrm{GHz}$ computer with $4.00 \mathrm{~GB}$ RAM. A real example from Hasani et al. [15] is used to investigate the applicability of the proposed model (see Appendix A). Information regarding the size of the problem is presented in Table 2, and the size of the coded model in GAMS is presented in Table 3.

In this model, the uncertainty of product demand, the number of products that need repair (return rate), and the cause of failure are considered through a scenario-based optimization approach. Scenario building requires a broad spectrum of knowledge and opinions from multidisciplinary team members, or in other words, experts [32]. In this research, we asked the experts to provide us with pessimistic, realistic, and optimistic values for uncertain parameters. The experts suggested five values for demand and the return rate (very low, low, medium, high, very high) and two values for the probability that part $j$ is the failure cause of product $i$. Hence, five, 
TABLE 4. Results of solving the proposed model with $\lambda=0.8$.

\begin{tabular}{lll}
\hline \hline Decision variable & \multicolumn{2}{l}{ Optimal quantity } \\
\hline & $j=1$ & 2012 \\
& $j=2$ & 1614 \\
The average number of part & $j=3$ & 1229 \\
remanufactured per scenario & $j=4$ & 3337 \\
& $j=5$ & 2032 \\
& sum & 10224 \\
\hline \multirow{2}{*}{ The average number of part } & $j=1$ & 1604 \\
transported to the service & $j=3$ & 963 \\
center per scenario & $j=4$ & 2310 \\
& $j=5$ & 1040 \\
& sum & 7213 \\
\hline
\end{tabular}

five, and $2^{5}$ (2 levels for each part) values are considered for every parameter, respectively. Thus, 800 possible scenarios are generated, of which more than $80 \%$ are compatible.

The high number of scenarios raises the complexity of the problem and reduces the efficiency of the solution. Also, in principle, only a few substantially different scenarios are needed [23]. Thus, it is suggested to use scenario reduction techniques to reduce the number of scenarios. One of the methods for reducing the number of scenarios is the clustering method. In the present research, similar to the research by Pishvaee et al. [26], the Fuzzy C-Means clustering method has been employed. The Fuzzy C-Means clustering method was developed by Dunn [6] and improved by Bezdek [3]. This method is as follows:

$$
\begin{array}{ll}
\min & J=\sum_{i=1}^{c} \sum_{k=1}^{n} u_{i k}^{m}\left\|x_{k}-v_{i}\right\|^{2} \\
\text { s.t. : } & \\
\qquad \sum_{i=1}^{c} u_{i k}=1, \quad \forall k=1, \ldots, n \\
v_{i}=\frac{\sum_{k=1}^{n} u_{i k}^{m} x_{k}}{\sum_{k=1}^{n} u_{i k}^{m}} \\
0 \leq u_{i k} \leq 1, \quad \forall i, k .
\end{array}
$$

In the objective function (5.1), $m$ is a fuzzifier that is a real number greater than 1 . In most cases, number 2 is chosen for $m . x_{k}$ is the $k$ th sample and $v_{i}$ is the representative or center of the $i$ th cluster. $u_{i k}$ denotes the amount of belonging of the $i$ th sample in the $k$ th cluster. Sign $\|*\|$ is the similarity amount (distance) of the sample with the center of the cluster, and any function that represents the similarity of sample and center of the cluster can be used. From $u_{i k}$ we can define a $U$ matrix with $c$ rows and $n$ columns, and its components can have any value between 0 and 1 . If all the components of the matrix $U$ are 0 or 1 , the algorithm is similar to the classic hard c-means. Equation (5.2) states that the sum of each column's components must be equal to 1. Equation (5.3) calculates the center of each cluster, and equation (5.4) determines the acceptable range for $u_{i k}$.

In this paper, scenarios are grouped into ten fuzzy clusters using the Fuzzy C-Means Clustering Algorithm in MATLAB software. In other words, the number of scenarios has been reduced to 10 scenarios. Implementation of the proposed model with ten scenarios in the GAMS software takes about $4 \mathrm{~h}$.

The optimal solution of the proposed model when $\lambda$ equals 0.8 is presented in Table 4 . In the optimal solution, in Period II, spare parts are supplied using two options: 


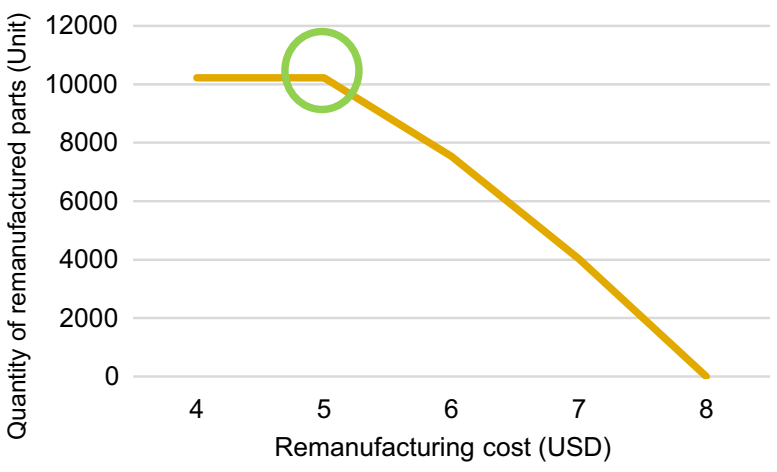

FiguRE 2. The number of remanufactured parts when remanufacturing cost increases.

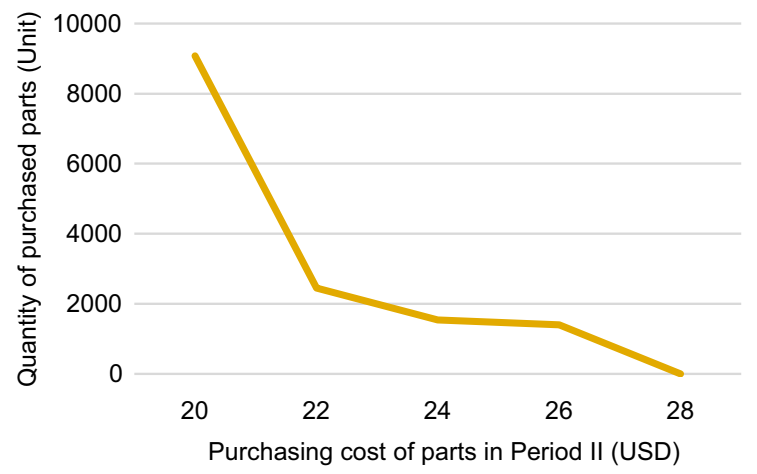

FIgURE 3. The number of purchased parts from alternative suppliers when purchasing price increases.

- Producing or purchasing extra parts in Period I to satisfy spare parts demand in Period II.

- And remanufacturing.

Overall, 10224 parts are remanufactured to meet the demand for after-sales services. Also, 7213 new parts are transported to service centers, from which 2895 parts are stored to be used in Period II. The third option, "purchasing parts just in time they were needed from other suppliers," is not optimal. It should be noted that in the optimal solution, three collecting/remanufacturing centers are opened with the lowest capacity level.

In order to validate the results, sensitivity analysis is done regarding three parameters, including (1) remanufacturing cost, (2) Purchasing price of parts in Period II, and (3) Mulvey's coefficient.

\subsection{Sensitivity analysis to remanufacturing cost}

The effect of increasing and decreasing remanufacturing costs on the number of remanufactured parts is shown in Figure 2. In this real example, when the remanufacturing cost reaches eight dollars, the quantity of remanufactured parts falls to zero. In these circumstances, the needed parts for after-sales services are provided through purchasing/producing extra parts in Period II. As is shown in Figure 2, the number of defective parts that can be remanufactured is a limiting factor.

\subsection{Sensitivity analysis to the purchasing price of parts in Period II}

The effect of increasing and decreasing purchasing prices of parts in Period II is shown in Figure 3. In this real example, the third option, "purchasing parts just in time they were needed from other suppliers," is not 
TABLE 5. Optimal results for different values of $\lambda$.

\begin{tabular}{|c|c|c|c|c|c|c|}
\hline Value of $\lambda$ & $\lambda=1$ & $\lambda=0.8$ & $\lambda=0.5$ & $\lambda=0.3$ & $\lambda=0.1$ & $\lambda=0$ \\
\hline Objective function & $1.80294 \mathrm{E}+14$ & $1.80294 \mathrm{E}+14$ & $1.83981 \mathrm{E}+14$ & $1.83982 \mathrm{E}+14$ & $1.86741 \mathrm{E}+14$ & $1.89542 \mathrm{E}+14$ \\
\hline Opening costs & 300000 & 300000 & 320000 & 340000 & 440000 & 750000 \\
\hline $\begin{array}{l}\text { tion for collecting / } \\
\text { remanufacturing cen- } \\
\text { ters }\end{array}$ & $\begin{array}{l}\text { with the lowest } \\
\text { capacity level }\end{array}$ & $\begin{array}{l}\text { with the lowest } \\
\text { capacity level }\end{array}$ & $\begin{array}{l}\text { capacity level } 1 \\
\text { and one center } \\
\text { with capacity } \\
\text { level } 2\end{array}$ & $\begin{array}{l}\text { capacity level } 1 \\
\text { and two centers } \\
\text { with capacity } \\
\text { level } 2\end{array}$ & $\begin{array}{l}\text { capacity level } 1 \\
\text { and two centers } \\
\text { with capacity } \\
\text { level } 2\end{array}$ & capacity level 3 \\
\hline
\end{tabular}

TABLE 6. The effect of remanufacturing on costs.

\begin{tabular}{ll}
\hline \hline & Purchasing and producing costs of parts \\
\hline With remanufacturing & $3.652331 \mathrm{E}+08$ \\
Without remanufacturing & $4.058146 \mathrm{E}+08$ \\
\hline
\end{tabular}

employed when the difference between purchasing price in Period I and II is more than $30 \%$. Also, this option has the last priority for supplying spare parts.

\subsection{Sensitivity analysis to the parameter $\lambda$}

The results of the proposed model with different values of $\lambda$ are shown in Table 5 . This parameter determines the relative importance of the mean of the objective functions versus the standard deviation. As is shown in this table, reducing the value of $\lambda$ increases opening costs.

We also investigated the economic benefits of remanufacturing. As shown in Table 6 , remanufacturing reduces purchasing and producing costs of parts by $10 \%$.

It should be noted that remanufacturing does not always reduce costs. In this example, remanufacturing is cost-efficient when the remanufacturing cost is equal to or less than $23 \%$ of the production cost. When the cost of remanufacturing is equal to or less than $15 \%$ of the production cost, all parts that can be remanufactured, will be remanufactured. Moreover, as shown in Figure 3, the third option, purchasing parts at a higher price in Period II, is only used if the cost of purchasing is equal to or less than $30 \%$ of the production cost.

\section{Conclusions}

Since many maintenance and repair activities require spare parts, accessibility of spare parts can highly affect service response speed and hence the quality of after-sales services. When a product is being produced, its spare parts can simultaneously be produced within the same manufacturing system. However, when a product reaches the end of its life cycle (Decline Stage) and is no longer being manufactured, supplying spare parts becomes more challenging. In the present study, a scenario-based optimization model was developed for planning the physical flow of products and components and redesigning of sales and after-sales services closed-loop network, considering three different option for supplying spare parts: (1) producing or purchasing extra parts (at a lower price) while the product and its components are still being produced and storing them for later consumption, (2) remanufacturing defective parts, and (3) purchasing parts just in time they were needed (at a higher price) from other suppliers. For this aim, the planning horizon is divided into two periods (based on the availability of production facilities).

Since design decisions are strategic decisions that have long-term effects on the performance of a supply chain, considering these uncertainties is crucial. Thus, in this paper, three parameters, including demand, the return rate, and failure causes, are considered to be uncertain. The scenario-based optimization approach developed by Mulvey et al. [20] has been employed to deal with existing uncertainties. 
Applicability and advantages of the proposed model are investigated using a real numerical example from the literature. The results indicate that extra production/procurement and remanufacturing are preferred to the third option. The third option is only employed when the difference between the purchasing price of parts in Period I and II is less than $30 \%$. Also, at least three collecting/remanufacturing facilities should be opened for the remanufacturing of defective parts.

Considering other options for supplying spare parts after production is stopped, distinguishing between remanufactured and new components, as well as studying the benefits of remanufacturing from an environmental point of view, are possible issues for future researches.

\section{Appendix A.}

In this paper, A real example from Hasani et al. [15] is used to investigate the applicability of the proposed model. Table A.1 provides the information regarding the Parameters' values. Note that all costs are in USD.

TABLE A.1. Information regarding other parameters' values.

\begin{tabular}{|c|c|c|c|c|}
\hline Parameter & & & Value & \\
\hline \multirow{2}{*}{$\varphi_{i j}$} & $i=1$ & & & $i=2$ \\
\hline & $\forall j \in\{1,2,3\}=1$ & & & $\forall j \in\{4,5\}=1$ \\
\hline \multirow[t]{4}{*}{$\pi_{i j}$} & $i=1$ & & & $i=2$ \\
\hline & $j=4 \quad 0.85$ & & & $j=1 \quad 0.8$ \\
\hline & $j=5 \quad 0.95$ & & & $j=2 \quad 0.9$ \\
\hline & & & & $j=3 \quad 0.7$ \\
\hline \multirow{2}{*}{\multicolumn{2}{|c|}{$\mathrm{RPC}_{j l t}$}} & \multirow{2}{*}{\multicolumn{2}{|c|}{$\begin{array}{l}\forall j, l, t=20 \\
\text { Alternative Supplier }=60\end{array}$}} & \\
\hline & & & & \\
\hline \multicolumn{2}{|l|}{$\mathrm{PRCO}_{i t}$} & \multicolumn{2}{|c|}{$\forall i=30$} & \\
\hline \multicolumn{2}{|l|}{$\mathrm{PRC}_{j c t}$} & \multicolumn{2}{|c|}{$\forall j, c, t=5$} & \\
\hline \multicolumn{2}{|l|}{$\mathrm{RPCM}_{m l t}$} & \multicolumn{2}{|c|}{$\forall m, l, t=2$} & \\
\hline \multicolumn{2}{|l|}{$\mathrm{PRCOJ}_{j p t}$} & \multicolumn{2}{|c|}{$\forall j, p, t=5$} & \\
\hline \multicolumn{2}{|l|}{$\mathrm{SV}_{j t}$} & \multicolumn{2}{|c|}{$\forall j, t=2$} & \\
\hline \multicolumn{2}{|l|}{$\mathrm{HCPO}_{i t}$} & \multicolumn{2}{|c|}{$\forall i, t=2$} & \\
\hline \multicolumn{2}{|l|}{$\mathrm{HCSO}_{j t}$} & \multicolumn{2}{|c|}{$\forall j, t=1.5$} & \\
\hline \multicolumn{2}{|l|}{$\operatorname{HCSS}_{j t}$} & \multicolumn{2}{|c|}{$\forall j, t=1.5$} & \\
\hline \multicolumn{2}{|l|}{$\mathrm{HCSC}_{j t}$} & \multicolumn{2}{|c|}{$\forall j, t=1$} & \\
\hline \multicolumn{2}{|l|}{$\mathrm{HCRC}_{j t}$} & \multicolumn{2}{|c|}{$\forall j, t=2$} & \\
\hline \multicolumn{2}{|l|}{$\mathrm{TC}_{i r t}$} & \multicolumn{2}{|c|}{$\forall i, r, t=0.25$} & \\
\hline $\mathrm{TCB}_{j l t}$ & & $\forall j, l$, & 0.05 & \\
\hline $\mathrm{TCM}_{m l p t}$ & & $\forall m, l$ & $t=0.01$ & \\
\hline $\mathrm{TCBJ}_{j p t}$ & & $\forall j, p$ & $=0.03$ & \\
\hline $\mathrm{TCN}_{j s t}$ & & $\forall j, s$, & $=0.05$ & \\
\hline $\mathrm{TCR}_{j c s t}$ & & $\forall j, c$, & $=0.05$ & \\
\hline $\mathrm{TCF}_{j s c t}$ & & $\forall j, s$, & $=0.03$ & \\
\hline $\mathrm{IC}_{i}$ & & $\forall i=$ & & \\
\hline $\operatorname{Capj}_{j p t}$ & & $t=1$ & $\forall j, p=40000$ & \\
\hline & & $t=2$ & $\forall j, p=40000$ & \\
\hline & & $t=3$ & $\forall j, p=0$ & \\
\hline & & $t=4$ & $\forall j, p=0$ & \\
\hline $\mathrm{Capm}_{p}$ & & $\forall p=$ & 000 & \\
\hline Capnop $_{p}$ & & $\forall p=$ & 000 & \\
\hline $\mathrm{Capml}_{m l t}$ & & $t=1$ & $\forall m, l=40000$ & \\
\hline & & $t=2$ & $\forall m, l=40000$ & \\
\hline & & $t=3$ & $\forall m, l=0$ & \\
\hline & & $t=4$ & $\forall m, l=0$ & \\
\hline
\end{tabular}


TABLE A.1. (continued.)

\begin{tabular}{|c|c|c|c|c|}
\hline Parameter & & & Value & \\
\hline \multirow[t]{5}{*}{$\operatorname{Cap}_{i t}$} & $i=1$ & & & $i=2$ \\
\hline & $t=1 \quad 500000$ & & & $t=1 \quad 500000$ \\
\hline & $t=2 \quad 500000$ & & & $t=2 \quad 500000$ \\
\hline & $t=3 \quad 0$ & & & $t=3 \quad 0$ \\
\hline & $t=4 \quad 0$ & & & $t=4 \quad 0$ \\
\hline \multirow[t]{5}{*}{$\operatorname{Capr}_{j c v t}$} & $v=3, \forall j, c$ & \multicolumn{2}{|r|}{$v=2, \forall j, c$} & $v=1, \forall j, c$ \\
\hline & $t=1 \quad 0$ & $t=1$ & 0 & $t=1 \quad 0$ \\
\hline & $t=2 \quad 0$ & $t=2$ & 0 & $t=2 \quad 0$ \\
\hline & $t=3 \quad 1500$ & $t=3$ & 1000 & $t=3 \quad 7500$ \\
\hline & $t=4 \quad 1500$ & $t=4$ & 1000 & $t=4 \quad 7500$ \\
\hline Cappo & & \multicolumn{2}{|c|}{$[600000,600000,0,0]$} & \\
\hline Capno & & \multicolumn{2}{|c|}{$[600000,600000,0,0]$} & \\
\hline \multirow[t]{3}{*}{$\operatorname{Capfc}_{c v}$} & & $v=1$ & $\forall c=6000$ & \\
\hline & & $v=2$ & $\forall c=8000$ & \\
\hline & & $v=3$ & $\forall c=11000$ & \\
\hline \multirow[t]{3}{*}{$\operatorname{Caprc}_{c v}$} & & $v=1$ & $\forall c=5000$ & \\
\hline & & $v=2$ & $\forall c=7000$ & \\
\hline & & $v=3$ & $\forall c=10000$ & \\
\hline Capns $_{s}$ & & \multicolumn{2}{|c|}{$\forall t=10000$} & \\
\hline \multirow[t]{4}{*}{$\mathrm{Capl}_{j l t}$} & & $t=1$ & $\forall j, l=20000$ & \\
\hline & & $t=2$ & $\forall j, l=20000$ & \\
\hline & & $t=3$ & $\forall j, l=0$ & \\
\hline & & $t=4$ & $\forall j, l=0$ & \\
\hline \multirow[t]{3}{*}{$\mathrm{CC}_{c m}$} & & $m=1$ & $\forall c=100000$ & \\
\hline & & $m=2$ & $\forall c=120000$ & \\
\hline & & $m=3$ & $\forall c=150000$ & \\
\hline
\end{tabular}

\section{REFERENCES}

[1] S.H. Amin and G. Zhang, A multi-objective facility location model for closed-loop supply chain network under uncertain demand and return. Appl. Math. Model. 37 (2013) 4165-4176.

[2] J. Ashayeri, N. Ma and R. Sotirov, The redesign of a warranty distribution network with recovery processes. Transp. Res. Part E: Logistics Transp. Rev. 77 (2015) 184-197.

[3] J.C. Bezdek, Pattern Recognition with Fuzzy Objective Function Algorithms, in Advanced Applications in Pattern Recognition. Springer, New York, NY (1981).

[4] E. Dehghani, M.S. Pishvaee and M.S. Jabalameli, A hybrid Markov process-mathematical programming approach for joint location-inventory problem under supply disruptions. RAIRO:OR 52 (2018) 1147-1173.

[5] F. Du and G.W. Evans, A bi-objective reverse logistics network analysis for post-sale service. Comput. Oper. Res. 35 (2008) 2617-2634.

[6] J.C. Dunn, A fuzzy relative of the ISODATA process and its use in detecting compact well-separated clusters. J. Cybern. 3 (1973) 32-57.

[7] M.B. Fakhrzad and F. Goodarzian, A fuzzy multi-objective programming approach to develop a green closed-loop supply chain network design problem under uncertainty: modifications of imperialist competitive algorithm. RAIRO:OR 53 (2019) 963-990.

[8] M. Fazli-Khalaf and A. Hamidieh, A robust reliable forward-reverse supply chain network design model under parameter and disruption uncertainties. Int. J. Eng.-Trans. B: App. 30 (2017) 1160-1169.

[9] M. Fazli-Khalaf and N.G. Nemati, A socially responsible supplier selection model under uncertainty: case study of pharmaceutical department of an Iranian hospital. Int. J. Logistics Syst. Manage. 32 (2019) 69-90.

[10] M. Fazli-Khalaf, B. Naderi and M. Mohammadi, Design of a reliable supply chain network with responsiveness considerations under uncertainty: case study of an Iranian tire manufacturer. Special issue: 14th International Industrial Engineering Conference. J. Ind. Syst. Eng. 11 (2018) 120-131.

[11] M. Fazli-Khalaf, K. Fathollahzadeh, A. Mollaei, B. Naderi and M. Mohammadi, A robust possibilistic programming model for water allocation problem. RAIRO:OR 53 (2019) 323-338.

[12] M. Fazli-Khalaf, S.K. Chaharsooghi and M.S. Pishvaee, A new robust possibilistic programming model for reliable supply chain network design: a case study of lead-acid battery supply chain. RAIRO-OR $\mathbf{5 3}$ (2019) 1489-1512.

[13] J. Ghahremani-Nahr, R. Kian and E. Sabet, A robust fuzzy mathematical programming model for the closed-loop supply chain network design and a whale optimization solution algorithm. Expert Syst. App. 116 (2019) 454-471. 
[14] A. Hamidieh, A. Arshadikhamseh and M. Fazli-Khalaf, A robust reliable closed loop supply chain network design under uncertainty: a case study in equipment training centers. Int. J. Eng. Trans. A Basics 31 (2017) 648-658.

[15] A. Hasani, S.H. Zegordi and E. Nikbakhsh, Robust closed-loop supply chain network design for perishable goods in agile manufacturing under uncertainty. Int. J. Prod. Res. 50 (2012) 4649-4669.

[16] S.T. John, R. Sridharan and P.R. Kumar, Reverse logistics network design: a case of mobile phones and digital cameras. Int. J. Adv. Manuf. Technol. 94 (2018) 615-631.

[17] T.-Y. Liao, Reverse logistics network design for product recovery and remanufacturing. Appl. Math. Model. 60 (2018) $145-163$.

[18] S.-H. Liao, C.-L. Hsieh and W.-C. Ho, Multi-objective evolutionary approach for supply chain network design problem within online customer consideration. RAIRO:OR 51 (2017) 135-155.

[19] A. Majumder, C.K. Jaggi and B. Sarkar, A multi-retailer supply chain model with backorder and variable production cost. RAIRO:OR 52 (2018) 943-954.

[20] J.M. Mulvey, R.J. Vanderbei and S.A. Zenios, Robust optimization of large-scale systems. Oper. Res. 43 (1995) $264-281$.

[21] D.N.P. Murthy, O. Solem and T. Roren, Product warranty logistics: issues and challenges. Eur. J. Oper. Res. 156 (2004) $110-126$.

[22] A. Mutha and S. Pokharel, Strategic network design for reverse logistics and remanufacturing using new and old product modules. Comput. Ind. Eng. 56 (2009) 334-346.

[23] T.G. Nguyen, J.-L. de Kok and M.J. Titus, A new approach to testing an integrated water systems model using qualitative scenarios. Environ. Model. Softw. 22 (2007) 1557-1571.

[24] R. Piplani and A. Saraswat, Robust optimisation approach to the design of service networks for reverse logistics. Int. J. Prod. Res. 50 (2012) 1424-1437.

[25] M.S. Pishvaee and S.A. Torabi, A possibilistic programming approach for closed-loop supply chain network design under uncertainty. Fuzzy Sets Syst. 161 (2010) 2668-2683.

[26] M.S. Pishvaee, M. Fathi and F. Jolai, A fuzzy clustering-based method for scenario analysis in strategic planning: the case of an Asian pharmaceutical company. S. Afr. J. Bus. Manage. 39 (2008) 21-31.

[27] M.S. Pishvaee, J. Razmi and S.A. Torabi, Robust possibilistic programming for socially responsible supply chain network design: a new approach. Fuzzy Sets Syst. 206 (2012) 1-20.

[28] M. Ramezani, M. Bashiri and R. Tavakkoli-Moghaddam, A new multi-objective stochastic model for a forward/reverse logistic network design with responsiveness and quality level. Appl. Math. Model. 37 (2013) 328-344.

[29] E. Rezaei, M.M. Paydar and A.S. Safaei, Customer relationship management and new product development in designing a robust supply chain. RAIRO:OR 54 (2020) 369-391.

[30] N. Saccani, P. Johansson and M. Perona, Configuring the after-sales service supply chain: a multiple case study. Int. J. Prod. Econ. 110 (2007) 52-69.

[31] N. Sahebjamnia, A.M. Fathollahi-Fard and M. Hajiaghaei-Keshteli, Sustainable tire closed-loop supply chain network design: hybrid metaheuristic algorithms for large-scale networks. J. Cleaner Prod. 196 (2018) 273-296.

[32] P. Schwab, F. Cerutti and U.H. von Reibnitz, Foresight-using scenarios to shape the future of agricultural research. Foresight 5 (2003) 55-61.

[33] H. Soleimani, K. Govindan, H. Saghafi and H. Jafari, Fuzzy multi-objective sustainable and green closed-loop supply chain network design. Comput. Ind. Eng. 109 (2017) 191-203.

[34] B. Vahdani, J. Razmi and R. Tavakkoli-Moghaddam, Fuzzy possibilistic modeling for closed loop recycling collection networks. Environ. Model. Assess. 17 (2012) 623-637.

[35] S. Verstrepen, D. Deschoolmeester and R.J. Van den Berg, Servitization in the automotive sector: creating value and competitive advantage through service after sales. In: Global Production Management. Vol. 24 of: IFIP The International Federation for Information Processing. Springer, Boston, MA (1999) 538-545.

[36] C.-S. Yu and H.-L. Li, A robust optimization model for stochastic logistic problems. Int. J. Prod. Econ. 64 (2000) $385-397$.

[37] L.J. Zeballos, C.A. Méndez and A.P. Barbosa-Povoa, Integrating decisions of product and closed-loop supply chain design under uncertain return flows. Comput. Chem. Eng. 112 (2018) 211-238. 